\title{
pH-Cycling Models to Evaluate the Effect of Low Fluoride Dentifrice on Enamel De- and Remineralization
}

\author{
Celso Silva QUEIROZ ${ }^{1}$ \\ Anderson Takeo HARA ${ }^{2}$ \\ Adriana Franco PAES LEME ${ }^{1}$ \\ Jaime Aparecido CURY ${ }^{1}$ \\ ${ }^{1}$ Department of Physiological Sciences, School of Dentistry of Piracicaba, \\ State University of Campinas, Piracicaba, SP, Brazil \\ ${ }^{2}$ Department of Preventive and Community Dentistry, Oral Health Research Institute, \\ Indiana University School of Dentistry, Indianapolis, IN, USA
}

\begin{abstract}
Since the currently available pH-cycling models do not differentiate the anti-caries potential of dentifrices with low fluoride (F) concentration, two models were developed and tested in the present. Bovine enamel blocks were subjected to the models and treated with F solutions containing from 70 to $280 \mu \mathrm{g} \mathrm{F} / \mathrm{mL}$ in order to validate them in terms of dose-response effect. The models were also tested by evaluating the dentifrices Colgate Baby ( $500 \mu \mathrm{g} \mathrm{F} / \mathrm{g}$, as a low fluoride dentifrice), Tandy (1,100 $\mu \mathrm{g}$ F/g, as an active Fdentifrice) and Crest (1,100 $\mu \mathrm{g} \mathrm{F/g}$, as positive control). Enamel mineral loss or gain was assessed by surface and cross-sectional microhardness, and lesion depth was analyzed by polarized light microscopy. The pH-cycling models showed F dose-response effect either reducing enamel demineralization or enhancing remineralization. The low $\mathrm{F}$ dentifrice presented anti-caries potential, but it was not equivalent to the dentifrices containing $1,100 \mu \mathrm{g} \mathrm{F} / \mathrm{g}$. These data suggest that the models developed in this study were able to evaluate the anti-caries potential of low $\mathrm{F}$ dentifrice either on resistance to demineralization or on enhancement of remineralization.
\end{abstract}

Key Words: demineralization, remineralization, fluoride, dentifrice.

\section{INTRODUCTION}

In spite of the progress of in situ and in vivo research in cariology, laboratory tests are still widely used to evaluate dental caries, mainly the effect of fluoride (F) on inhibition of enamel-dentin demineralization and enhancement of remineralization. Among these protocols, there is a consensus that $\mathrm{pH}$-cycling models may be used because they mimick caries development in vivo (1). Nevertheless, before using to estimate the anti-caries potential of $\mathrm{F}$ products, these models should be previously validated in terms of dose-response (2).

Therefore, the major focus of researchers has been the development of in vitro models that meet the suggested ADA guidelines associated with topical evaluations of fluoride (F) dentifrice (2). According to these guidelines (3), a pH-cycling model should show F doseresponse effect but, unfortunately, most publications referring to these models are abstracts rather than fulltext papers (2). Furthermore, according to ADA guidelines a pH-cycling model should show dose-response effect differentiating dentifrices containing 0,250 and $1,100 \mu \mathrm{g} \mathrm{F} / \mathrm{g}$. Therefore, it is not mandatory that these models are able to differentiate the anti-caries effect of a low F dentifrice containing 500-550 $\mu \mathrm{g} \mathrm{F/g}$ from the conventional $1,000-1,100 \mu \mathrm{g} \mathrm{F} / \mathrm{g}$, and the committee only recommended (3) that a $500 \mathrm{ppm} F$ treatment group could be included to obtain a "mini-dose-response".

As far as low $\mathrm{F}$ dentifrice is concerned, it has been suggested as an alternative to reduce the risks of dental fluorosis (4) because, although caries decline in developed and developing countries (5) is explained by 
widespread F-dentifrice use, it has also been considered to be a risk factor for fluorosis (6). However, in addition to the fact that the anti-caries efficiency of low $\mathrm{F}$ dentifrice is not clearly established (7), the in vitro models available to evaluate the anti-caries potential of $\mathrm{F}$ dentifrice are unable to differentiate the effect of low F dentifrice compared to the conventional 1,000-1,100 $\mu \mathrm{g} F / g$ range (8-9). Moreover, regarding the substrates used in these investigations, although bovine enamel has several advantages over human enamel (10), it has not been thoroughly characterized in a $\mathrm{pH}$-cycling study (11). Therefore, the goal of this study was to develop, validate and test $\mathrm{pH}$-cycling models to evaluate the anticaries potential of low $\mathrm{F}$ dentifrices either to inhibit demineralization or to enhance remineralization, using bovine enamel as substrate.

\section{MATERIAL AND METHODS}

\section{Experimental Design}

Four independent studies were carried out. For two of them, fluoride solutions $(0,70,140$ and $280 \mu \mathrm{g}$ $\mathrm{F} / \mathrm{mL}$ ) were used to validate the models to evaluate $\mathrm{F}$ effect on inhibition of enamel demineralization (named demineralizing $\mathrm{pH}$-cycling model) and to enhance remineralization (named remineralizing $\mathrm{pH}$-cycling model). The other two studies used the validated models testing 4 dentifrices (3 fluoridated commercial dentifrices and 1 non-fluoridated control formulation) in their ability to interfere with enamel de- and remineralization.

The experimental units were bovine enamel blocks. Independent comparisons among treatments of either fluoride solutions or dentifrices were done, considering the response variables: percentage of surface microhardness loss (\%SML), integrated mineral loss $(\Delta \mathrm{Z})$ and lesion depth (LD), for the demineralizing model; and percentage of surface microhardness recovery (\%SMR), percentage of integrated mineral recovery $(\% \Delta \mathrm{Z})$ and LD for the remineralizing model. Additionally, analyses of the $\mathrm{F}$ dose-response effect were performed with the fluoride solutions, in both models.

\section{Demineralizing Solution Preparation}

Firstly, 0.05 M acetate buffer pH 5.0, 50\% saturated with respect to enamel solubility was prepared. In this solution, it was detected $1.28 \pm 0.058$ $\mathrm{mmol} / \mathrm{L}$ of $\mathrm{Ca}, 0.74 \pm 0.005 \mathrm{mmol} / \mathrm{L}$ of inorganic phosphorus $\left(\mathrm{P}_{\mathrm{i}}\right)$ and $0.023 \pm 0.006 \mu \mathrm{g} / \mathrm{mL}$. From these results, $0.05 \mathrm{~mol} / \mathrm{L}$ acetate buffer, $\mathrm{pH} 5.0$ and containing $1.28 \mathrm{mmol} / \mathrm{L} \mathrm{Ca}, 0.74 \mathrm{mmol} / \mathrm{L}_{\mathrm{i}}$ and $0.03 \mu \mathrm{g} \mathrm{F} / \mathrm{mL}$ was prepared from the salts $\mathrm{Ca}\left(\mathrm{NO}_{3}\right)_{2} \cdot 4 \mathrm{H}_{2} \mathrm{O}, \mathrm{KH}_{2} \mathrm{PO}_{4}$ and $\mathrm{NaF}$, respectively. This demineralizing solution was used in both $\mathrm{pH}$-cycling models (de- and remineralizing) and also to induce caries-like lesions on enamel blocks subjected to the $\mathrm{pH}$-cycling caries reversal model.

\section{Enamel Block Preparation}

Flattened and polished bovine enamel blocks $(4 \times 4 \times 3 \mathrm{~mm})$ were prepared (12). An adhesive strip (2.0 $\mathrm{x} 4.0 \mathrm{~mm}$ ) was attached to the enamel and the remaining surfaces of the block were coated with an acid-resistant varnish, so that an area of $8.0 \mathrm{~mm}^{2}$ was exposed to the treatments. Baseline enamel surface microhardness was determined (13) and 197 enamel blocks with hardness of $353.4 \pm 12.2 \mathrm{~kg} / \mathrm{mm}^{2}$ were selected for this study.

\section{Demineralizing $\mathrm{pH}$-Cycling Model}

Model Validation - Dose-Response Test: Fiftytwo blocks were randomly assigned to 4 groups $(n=13)$ and submitted to one of the following treatments: distilled deionized water (DDW, as negative control) and solutions containing 70, 140 and $280 \mu \mathrm{g} \mathrm{F} / \mathrm{mL}$. These $\mathrm{F}(\mathrm{NaF})$ concentrations were chosen to simulate the dilution $(1: 3 \mathrm{w} / \mathrm{w})$ that occurs in the oral cavity when dentifrices containing 275, 550 and $1100 \mu \mathrm{g} \mathrm{F} / \mathrm{g}$, respectively, are used (14). The $\mathrm{pH}$-cycling regimen took 8 days, and the blocks were kept at $37^{\circ} \mathrm{C}$ for $4 \mathrm{~h}$ in the demineralizing solution and $20 \mathrm{~h}$ in the remineralizing solution. Twice a day (before and after immersion in the demineralizing solution), the blocks were washed with DDW and subjected to one of the groups of treatments for 5 min under agitation. After treatments, the blocks were washed and individually kept in the demineralizing solution. The remineralizing solution used contained 1.5 $\mathrm{mmol} / \mathrm{L} \mathrm{Ca}, 0.9 \mathrm{mmol} / \mathrm{L} \mathrm{P}, 150 \mathrm{mmol} / \mathrm{L} \mathrm{KCl}, 0.05 \mu \mathrm{g} \mathrm{F} /$ $\mathrm{mL}$ in $0.1 \mathrm{~mol} / \mathrm{L}$ Tris buffer, $\mathrm{pH} 7.0$. The proportion of demineralizing and remineralizing solutions per area of block was $6.25 \mathrm{~mL} / \mathrm{mm}^{2}$ and $3.12 \mathrm{~mL} / \mathrm{mm}^{2}$, respectively. On the 4th day, the de- and remineralizing solutions were replaced by fresh ones. After the 8th cycle, the blocks remained in the remineralizing solution for additional $24 \mathrm{~h}$ until the analyses (13). 
F-Dentifrice Evaluation. The effect of F dentifrice on inhibiting demineralization was tested using the same conditions described before. Forty blocks were randomly assigned to 4 groups $(n=10)$ that were subjected to one of the following treatments: non-fluoridated dentifrice (negative control); Colgate Baby (500 $\mu \mathrm{g} \mathrm{F} / \mathrm{g}$, as a low fluoride dentifrice, Colgate-Palmolive, São Bernardo do Campo, SP, Brazil); Tandy (1,100 $\mu \mathrm{g}$ $\mathrm{F} / \mathrm{g}$, as an active F-dentifrice, Colgate-Palmolive); and Crest Cavity Protection Regular $(1,100 \mu \mathrm{g} \mathrm{F} / \mathrm{g}$, as a positive control, considered a "gold standard", Procter \& Gamble, Cincinnati, OH, USA). The blocks were treated twice a day for $5 \mathrm{~min}$ with dentifrice/water slurries (1:3 w/w). All products were silica-based dentifrices.

\section{Remineralizing $\mathrm{pH}$-Cycling Model}

Caries-Like Lesion Formation. A preliminary study to induce caries-like lesions on bovine enamel blocks was conducted. Forty blocks were immersed individually in the previously described demineralizing solution $\left(2 \mathrm{~mL} / \mathrm{mm}^{2}\right.$ of enamel area) from 8 to $64 \mathrm{~h}$ and mineral loss was evaluated. The time of $32 \mathrm{~h}$ was chosen to induce caries-like lesion on enamel because the enamel blocks presented measurable caries-like subsurface lesions without surface erosion, allowing the evaluation of mineral loss or gain by determining surface microhardness. Next, 105 enamel blocks of known surface microhardness (SMH) (sound enamel) were subjected to the demineralizing solution for $32 \mathrm{~h}$, the SMH was again determined (demineralized enamel) and these blocks with caries-like lesions were used for the further analyses.

Model Validation - Dose-Response Test. Sixtyfive enamel blocks, presenting caries-like lesions, were randomly assigned to 5 groups $(n=13)$. Four groups were submitted to the same conditions already described for the $\mathrm{pH}$-cycling demineralizing model and the 5th extra-group was not submitted to any treatment and was kept for analysis of the baseline caries-like lesion. The $\mathrm{pH}$-cycling regimen took 8 days and this number of cycles was determined by pilot study since after 11 days in the remineralizing solution, there is maximum rehardening of enamel surface, irrespective of $F$ concentration used to enhance remineralization. The blocks were kept for $2 \mathrm{~h}$ in the demineralizing solution and for $22 \mathrm{~h}$ in remineralizing solution at $37^{\circ} \mathrm{C}$. Three times a day (9:00, 14:00 and 17:00 h), the blocks were washed with DDW and submitted for $1 \mathrm{~min}$ to one of the treatments under agitation. After the treatments, the blocks were washed again. On the 4th day, the de- and remineralizing solutions were replaced by fresh ones. After another 4day cycle, the enamel remineralization was evaluated.

F-Dentifrice Evaluation. Forty enamel blocks, presenting caries-like lesions, were randomly assigned to 4 groups $(n=10)$. They were subjected to the $\mathrm{pH}-$ cycling caries reversal model described before, and submitted to the dentifrices as already described for the pH-cycling demineralizing model.

\section{Microhardness Analysis}

After the demineralizing $\mathrm{pH}$-cycling and treatments, enamel SMH was again determined (12) and the $\%$ SML was calculated. Subsequently, all the blocks were longitudinally sectioned through the center and the cross-sectional microhardness was measured on the inner surface of one of the halves, to the determination of the area of mineral loss $(\Delta \mathrm{Z})(12)$. After the remineralizing $\mathrm{pH}$-cycling and treatments, $\mathrm{SMH}$ was again determined and percentage of SMH recovery (\%SMR) was calculated. Afterwards, all enamel blocks were longitudinally sectioned and prepared as described above. In one half of the specimens, the integrated mineral recovery value for each experimental group was calculated $\left(\Delta Z_{2}\right)$, compared to that $\left(\Delta Z_{1}\right)$ of the extra-group of enamel blocks presenting caries-like lesions and the percentage of integrated mineral recovery was calculated $\left(\% \Delta \mathrm{Z}=\Delta \mathrm{Z}_{1}-\Delta \mathrm{Z}_{2} \times 100 / \Delta \mathrm{Z}_{1}\right)$. The microhardness tester (Future-Tech FM Corp., Tokyo, Japan), coupled to FM-ARS software, was used for these analyses and a Knoop indenter was used with a 25-g load for $5 \mathrm{~s}$ (13).

\section{Polarized Light Microscopy Analysis}

Longitudinal sections of $100 \pm 10 \mu \mathrm{m}$ were obtained from the remaining half of each block. Sections were embedded in DDW, mounted on glass-slides and the artificial caries lesion depth was analyzed in a polarized light microscope (DM LSP, Leica, Wetzlar $\mathrm{GmbH}$, Germany), as previously detailed (15).

\section{Statistical Analysis}

The assumptions of equality of variances and normal distribution of errors were respectively checked 
with the Hartley and Shapiro-Wilks tests for all response variables. If necessary, data were transformed according to the Box-Cox method. The differences between the F-dentifrices or F-solutions treatments were evaluated by ANOVA and Tukey's test $(\alpha=0.05)$ for all variables. To test the dose-response effect of F-solutions, $\% \mathrm{SML}, \Delta \mathrm{Z}, \% \mathrm{SMR}, \% \Delta \mathrm{Z}$ and $\mathrm{LD}$ data were analyzed by ANOVA and regression analysis $(\alpha=0.05)$. The analyses were performed with the SAS System 8.01 software (SAS Institute Inc., Cary, NC, USA).
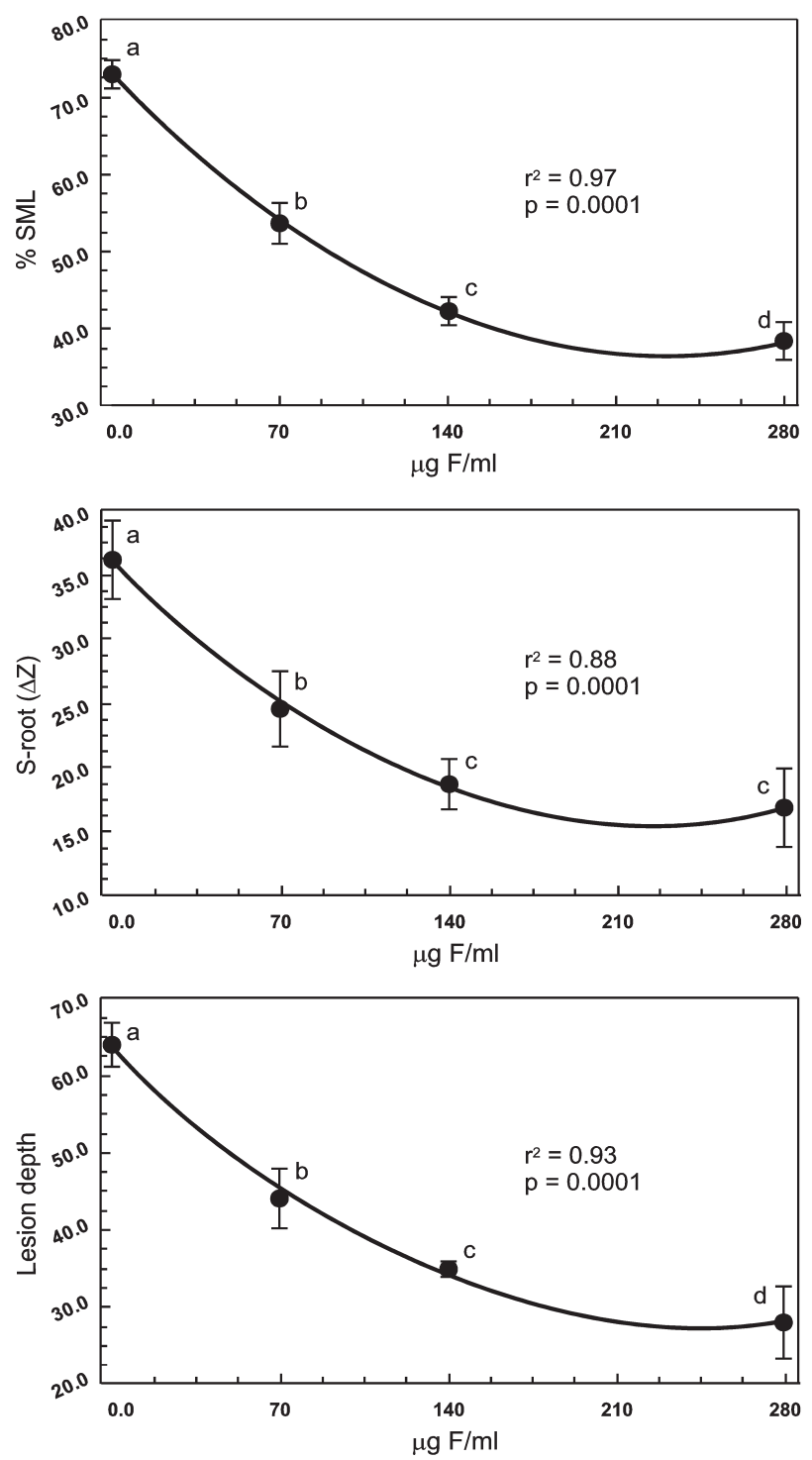

Figure 1. Effect of fluoride concentration $(\mu \mathrm{g} \mathrm{F} / \mathrm{mL})$ on reduction of enamel demineralization evaluated by surface microhardness (top), area of mineral loss (center) and lesion depth (bottom).

\section{RESULTS}

\section{Demineralizing $\mathrm{pH}$-Cycling Model}

$\Delta \mathrm{Z}$ data of both fluoride solution and fluoride dentifrice experiments were transformed according to the root-square function. Highly significant dose-response effects were found to the response variables (Fig. 1) throughout the increase of fluoride concentrations in the solutions, when data were adjusted to quadratic fits: \%SML $\left(\mathrm{R}^{2}=0.97 ; \mathrm{p}=0.0001\right), \Delta \mathrm{Z}\left(\mathrm{R}^{2}\right.$ $=0.88 ; \mathrm{p}=0.0001)$ and $\mathrm{LD}\left(\mathrm{R}^{2}=0.93 ; \mathrm{p}=0.0001\right)$. Table 1 shows that all F-dentifrices significantly reduced enamel demineralization, either evaluated by $\% \mathrm{SML}, \Delta \mathrm{Z}$ or LD, compared to the negative control group $(\mathrm{p}<0.05)$. However, the dentifrices containing $1,100 \mu \mathrm{g} \mathrm{F} / \mathrm{g}$ were more efficacious in reducing enamel demineralization than the low $\mathrm{F}$ dentifrice $(\mathrm{p}<0.05)$, but the active F-dentifrice and the positive control did not differ significantly $(\mathrm{p}>0.05)$.

\section{Remineralizing $\mathrm{pH}$-Cycling Model}

$\%$ SMR data of the fluoride solutions experiment

Table 1. Results (original values) according to the treatments with fluoride solutions $(n=13)$ or dentifrices $(n=10)$ for the $\mathrm{pH}$ cycling demineralizing model. (Means $\pm \mathrm{SD}$ ) .

\begin{tabular}{lrrr}
\hline $\begin{array}{l}\text { Treatment } \\
\text { groups with }\end{array}$ & \multicolumn{3}{c}{ Variables } \\
\cline { 2 - 4 } $\begin{array}{l}\text { F-solutions } \\
(\mu \mathrm{g} \mathrm{F} / \mathrm{mL})\end{array}$ & $\begin{array}{r}\% \mathrm{SML}^{\mathrm{b}} \\
\left(\mathrm{kg} / \mathrm{mm}^{2}\right)\end{array}$ & $\begin{array}{c}\Delta \mathrm{Z}^{\mathrm{c}} \\
(\mathrm{vol} . \% \min \mathrm{x} \mu)\end{array}$ & $\begin{array}{c}\mathrm{LD}^{\mathrm{d}} \\
(\mu \mathrm{m})\end{array}$ \\
\hline & & & \\
0 & $72.9 \pm 0.9$ & $1314.5 \pm 228.9$ & $64.0 \pm 1.8$ \\
70 & $53.7 \pm 1.7$ & $615.4 \pm 242.6$ & $44.1 \pm 5.9$ \\
140 & $42.2 \pm 1.6$ & $356.4 \pm 72.7$ & $35.0 \pm 1.0$ \\
280 & $38.4 \pm 1.1$ & $292.5 \pm 97.3$ & $28.1 \pm 6.5$
\end{tabular}

Dentifrices

$\left.\left.\begin{array}{llcl}\text { Negative control } & 74.8 \pm 8.2 & 1569.5 \pm 215.1 & 84.2 \pm 2.8 \\
\text { Low fluoride } & 47.7 \pm 10.1 & 789.1 \pm 122.1 & 50.6 \pm 4.6 \\
\text { Active dentifrice } & 33.8 \pm 4.3 \\
\text { Positive control } & 35.4 \pm 6.5\end{array}\right] \begin{array}{l}399.8 \pm 65.7 \\
376.4 \pm 125.1\end{array}\right]$\begin{tabular}{l}
$30.1 \pm 1.4$ \\
\hline
\end{tabular}

aFluoride solutions and dentifrices whose means are connected by brackets do not differ statistically $(\mathrm{p}<0.05)$; bercentage of surface microhardness loss; ${ }^{\circ}$ Integrated mineral loss; ${ }^{\mathrm{d}}$ Lesion depth. 
and $\Delta \mathrm{Z}$ data of the fluoride dentifrice experiment, were transformed according to the root-square and $\log _{10}$ functions, respectively. Highly significant dose-response effects were found to the response variables (Fig. 2) throughout the increase of the fluoride concentrations in the solutions, when data were adjusted to cubical: $\% \operatorname{SMR}\left(\mathrm{R}^{2}=0.86 ; \mathrm{p}=0.0001\right)$; and quadratic fits: $\% \Delta \mathrm{Z}$ $\left(\mathrm{R}^{2}=0.87 ; \mathrm{p}=0.0001\right)$ and $\mathrm{LD}\left(\mathrm{R}^{2}=0.80 ; \mathrm{p}=0.0001\right)$. Table 2 shows that all F-dentifrices presented higher $\% \mathrm{SMR}$, or $\% \Delta \mathrm{Z}$, and lower $\mathrm{LD}$ compared to the
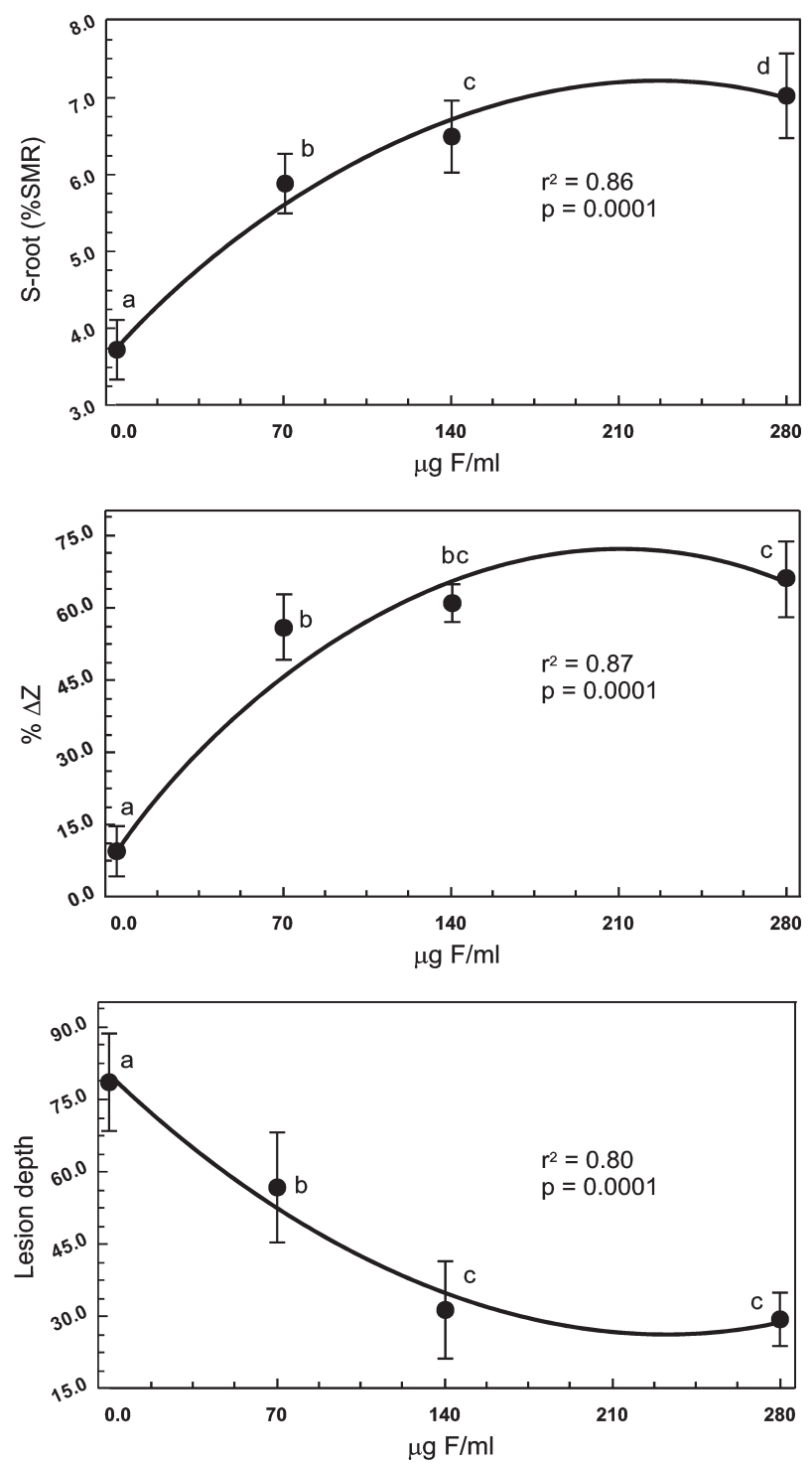

Figure 2. Effect of fluoride concentration $(\mu \mathrm{gF} / \mathrm{mL})$ on enhancement of enamel remineralization evaluated by surface microhardness (top), area of mineral recovery (center) and lesion depth (bottom). negative control group $(\mathrm{p}<0.05)$. The low $\mathrm{F}$ dentifrice showed lower efficacy in enhancing remineralization than the dentifrices containing $1,100 \mu \mathrm{g} \mathrm{F} / \mathrm{g}(\mathrm{p}<0.05)$, which did not differ statistically $(\mathrm{p}>0.05)$.

\section{DISCUSSION}

The $\mathrm{pH}$-cycling models developed were designed to evaluate in vitro the anti-caries potential of dentifrice with low fluoride $(\mathrm{F})$ concentration, either to reduce enamel demineralization or to enhance remineralization, compared to conventional dentifrice presenting 1,000$1,100 \mu \mathrm{g} \mathrm{F} / \mathrm{g}$. To validate them, F solutions of known concentrations similar those found during tooth brushing with F-dentifrice (14) were first used to evaluate the dose-response effect of $F$ on enamel. Next, using the developed $\mathrm{pH}$-cycling models, a commercially available low F-dentifrice was evaluated against a positive control dentifrice ("gold standard") and an active 1,100 $\mu \mathrm{g} \mathrm{F/g}$ Brazilian dentifrice $(15,16)$.

The findings showed that both $\mathrm{pH}$-cycling models developed in this study presented $\mathrm{F}$ dose-response effect for all analyzed variables (Tables 1 and 2, and

Table 2. Results (original values) according to the treatments with fluoride solutions $(n=13)$ or dentifrices $(n=10)$ for the $\mathrm{pH}$ cycling remineralizing model. (Means $\pm \mathrm{SD})^{\mathrm{a}}$.

\begin{tabular}{|c|c|c|c|}
\hline \multirow{2}{*}{$\begin{array}{l}\text { Treatment } \\
\text { groups with } \\
\text { F-solutions } \\
(\mu \mathrm{g} \mathrm{F} / \mathrm{mL})\end{array}$} & \multicolumn{3}{|c|}{ Variables } \\
\hline & $\begin{array}{l}\% \mathrm{SMR}^{\mathrm{b}} \\
\left(\mathrm{kg} / \mathrm{mm}^{2}\right)\end{array}$ & $\begin{array}{c}\% \Delta \mathrm{Z}^{\mathrm{c}} \\
(\text { vol. } \% \min \mathrm{x} \mu \mathrm{m})\end{array}$ & $\begin{array}{l}\mathrm{LD}^{\mathrm{d}} \\
(\mu \mathrm{m})\end{array}$ \\
\hline 0 & $13.9 \pm 2.7$ & $9.6 \pm 5.5$ & $78.4 \pm 5.2$ \\
\hline 70 & $34.5 \pm 4.7$ & $56.0 \pm 6.7$ & $56.9 \pm 1.4$ \\
\hline 140 & $42.1 \pm 6.2$ & $61.0 \pm 4.0_{-}$ & $31.4 \pm 2.7$ \\
\hline 280 & لـ $49.1 \pm 7.0$ & $65.8 \pm 8.8^{-}$ & $29.5 \pm 6.9$ \\
\hline
\end{tabular}

Dentifrices

\begin{tabular}{|c|c|c|c|}
\hline $\mathrm{Neg}$ & $9.1 \pm 3.2$ & $6.2 \pm 1.4$ & OT. \\
\hline Low & $26.2 \pm 2.2$ & $33.2 \pm 11.0$ & \pm 3.6 \\
\hline & 38.8 & $56.2 \pm$ & \\
\hline ositi & $40.9 \pm 3.2$ & $52.3 \pm 5.6$ & 20.7 \\
\hline
\end{tabular}

aFluoride solutions and dentifrices whose means are connected by brackets do not differ statistically ( $\mathrm{p}<0.05$ ); ${ }^{\text {bPercentage of surface }}$ microhardness recovery; ${ }^{\circ}$ Percentage of integrated mineral recovery; ${ }^{\mathrm{d}}$ Lesion depth. 
Figs. 1 and 2). This suggests that these pH-cycling models are adequate for studying in vitro fluoride effect on bovine enamel, either evaluating early caries by surface microhardness change or caries progression by cross-sectional microhardness or polarizing microscopy. The data are relevant because one of the barriers the use of bovine enamel in in vitro studies is the fact that its surface is susceptible to erosion (11). However, even human enamel is susceptible to erosion when subjected in vitro to $\mathrm{pH}$-cycling, and modification of the widely used models is required to evaluate early caries (13).

It should be emphasized that although our research group has developed other $\mathrm{pH}$-cycling models $(13,17)$ using human or bovine enamel as substrate, they have not been used to evaluate F products. The models developed in the present study, in addition to being of novel design, extended the previous results (17) for bovine enamel because they were tested using commercially available F-dentifrices, one of them considered as a "gold standard".

The Brazilian fluoride dentifrice Tandy, which contains $1,100 \mu \mathrm{g} \mathrm{F} / \mathrm{g}$, was equivalent to the positive control dentifrice Crest, reducing demineralization and enhancing remineralization of enamel (Tables 1-2). These findings have clinical relevance because this dentifrice is consumed by $20 \%$ of the young Brazilian population (18) and F-dentifrices have made an important contribution to caries decline in Brazil (5). Furthermore, this in vitro study confirms in situ findings about the anti-caries efficacy of this formulation $(15,16,19)$.

However, although the tested low F dentifrice was effective in reducing enamel demineralization and enhancing remineralization in comparison to the nonfluoridated negative control dentifrice, it did not have an equivalent performance to that of the positive control or the active dentifrice containing 1,100 $\mu \mathrm{g} \mathrm{F/g}$. Thus, although the low $\mathrm{F}$ dentifrice may be safer than the conventional one in terms of dental fluorosis risks, its use should be recommended according to the children's caries activity (20).

In conclusion, the findings of the present study suggest that the developed in vitro models using bovine enamel as substrate, in addition to presenting $\mathrm{F}$ doseresponse effect, were also able to evaluate the anticaries potential of a low $\mathrm{F}$ dentifrice, either to inhibit enamel demineralization or to enhance enamel remineralization, compared to the conventional dentifrice containing $1,100 \mu \mathrm{g} \mathrm{F} / \mathrm{g}$. Furthermore, these models could be used to evaluate the anti-caries potential of fluoride mouthrinse $(225 \mu \mathrm{g} \mathrm{F} / \mathrm{mL})$.

\section{RESUMO}

Tendo em vista que os modelos atuais de ciclagens de $\mathrm{pH}$ não diferenciam o potencial anti-cárie de dentifrícios com baixa concentração de fluoreto $(\mathrm{F})$, dois modelos foram desenvolvidos e testados. Blocos de esmalte bovino foram submetidos aos modelos e tratados com soluções de concentrações crescentes de $\mathrm{F}(70 \mathrm{a} 280 \mu \mathrm{g} \mathrm{F} / \mathrm{mL})$ para validar os modelos em termos de doseresposta. A seguir, os modelos foram testados avaliando o potencial anti-cárie dos dentifrícios Colgate Baby $(500 \mu \mathrm{g} \mathrm{F} / \mathrm{g}$, dentifrício de baixa concentração), Tandy (1.100 $\mu \mathrm{g} \mathrm{F/g}$, como controle ativo) e Crest (1.100 $\mu \mathrm{g} \mathrm{F/g}$, como controle positivo). Perda ou ganho de mineral pelo esmalte foi avaliada por microdureza e profundidade de lesão de cárie foi avaliada por microscopia de luz polarizada. Os modelos de ciclagens de $\mathrm{pH}$ desenvolvidos mostraram efeito do $\mathrm{F}$ dose-resposta quer seja na redução da desmineralização como na remineralização do esmalte. $\mathrm{O}$ dentifrício de baixa concentração de $\mathrm{F}$ mostrou ter potencial anti-cárie, o qual não foi equivalente aos dentifrícios contendo $1.100 \mu \mathrm{g} \mathrm{F} / \mathrm{g}$. Os resultados sugerem que os modelos desenvolvidos são capazes de avaliar o potencial anti-cárie de dentifrício de concentração reduzida de $\mathrm{F}$, quer seja na sua capacidade de aumentar a resistência do esmalte a desmineralização como na ativação da remineralização.

\section{ACKNOWLEDGEMENTS}

The authors would like to thank Dr. Livia MA Tenuta for the preliminary statistical analyses and Ms. Mariza JC Soares for laboratory assistance. The fourth author, authorized by State University of Campinas, was a scientific consultant to Kolynos do Brasil (now Colgate-Palmolive) during the time this study was conducted. This manuscript is part of a thesis submitted by the first author to the School of Dentistry of Piracicaba, University of Campinas (UNICAMP), in partial fulfillment of the requirements for the Doctorate degree in Dentistry (Cariology Area). This study was supported by CNPq (Proc.140225/20005) and FUNCAMP (Conv. 219).

\section{REFERENCES}

1. ten Cate JM. In vitro studies of the effects of fluoride on deand remineralization. J Dent Res 1990;69(Spec Iss):614-619.

2 . White DJ. The application of in vitro models to research on demineralization and remineralization of the teeth. Adv Dent Res 1995;9:175-193.

3. Proskin HM, Chilton NW, Kingman A. Interim report of the ad hoc committee for the consideration of statistical concerns related to the use of intra-oral models in submissions for product claims approval to the American Dental Association. J Dent Res 1992;71(Spec Iss):949-952.

4. Horowitz HS. The need for toothpastes with lower than conventional fluoride concentrations for preschool-aged children. J Public Health Dent 1992;52:216-221. 
5. Cury JA, Tenuta LMA, Ribeiro CCC, Paes Leme AF. The importance of fluoride dentifrices to the current dental caries prevalence in Brazil. Braz Dent J 2004;15:167-174.

6. Mascarenhas AK. Risk factors for dental fluorosis: a review of the recent literature. Pediatr Dent 2000;22:269-277.

7. Ammari AB, Bloch-Zupan A, Ashley PF. Systematic review of studies comparing the anti-caries efficacy of children's toothpaste containing $600 \mathrm{ppm}$ of fluoride or less with high fluoride toothpastes of $1,000 \mathrm{ppm}$ or above. Caries Res 2003;37:85-92.

8. Damato FA, Strang R, Stephen KW. Effect of fluoride concentration on remineralization of carious enamel: an in vitro pH-cycling study. Caries Res 1990;24:174-180.

9. Tandon S, Paul ST, Kiran M. Effect of low fluoride dentifrices on microhardness of sound enamel. In vitro study. Indian J Dent Res 1995;6:117-122.

10. Zero DT. In situ caries models. Adv Dent Res 1995;9:214230

11. Amaechi BT, Higham SM, Edgar WM. Factors affecting the development of carious lesions in bovine teeth in vitro. Arch Oral Biol 1998;43:619-628.

12. Cury JA, Rebelo MAB, Del Bel Cury AA, Derbyshire MTVC, Tabchoury CPM. Biochemical composition and cariogenicity of dental plaque formed in the presence of sucrose or glucose and fructose. Caries Res 2000;34:491-497.

13. Argenta RMO, Tabchoury CPM, Cury JA. A modified pHcycling model to evaluate fluoride effect on enamel deminer- alization. Braz Oral Res 2003;17:241-246.

14. Duke SA, Forward GC. The conditions occurring in vivo when brushing with toothpastes. Br Dent J 1982;152:52-54.

15. Hara AT, Queiroz CS, Paes Leme AF, Serra MC, Cury JA. Caries progression and inhibition in human and bovine root dentine in situ. Caries Res 2003;37:339-344.

16. Paes Leme AF, Dalcico R, Tabchoury CPM, Del Bel Cury AA, Rosalen PL, Cury JA. In situ effect of frequent sucrose exposure on enamel demineralization and on plaque composition after APF application and F dentifrice use. J Dent Res 2004;83:71-75

17. Vieira AEM, Delbem ACB, Sassaki KT, Rodrigues E, Cury JA, Cunha RF. Fluoride dose response in $\mathrm{pH}$-cycling models using bovine enamel. Caries Res 2005;39:514-520.

18. Paiva SM, Lima YBO, Cury JA. Fluoride intake by Brazilian children from two communities with fluoridated water. Community Dent Oral Epidemiol 2003;31:184-191.

19. Nobre-Dos-Santos M, Rodrigues LK, Del-Bel-Cury AA, Cury JA. In situ effect of a dentifrice with low fluoride concentration and low $\mathrm{pH}$ on enamel remineralization and fluoride uptake. J Oral Sci 2007;49:147-154.

20. Lima TJ, Ribeiro CC, Tenuta LM, Cury JA. Low-fluoride dentifrice and caries lesion control in children with different caries experience: a randomized clinical trial. Caries Res 2008;42:46-50

Accepted February 29, 2008 